\title{
PROXIMATE MECHANISMS OF SEXUAL SELECTION IN WOOD FROGS
}

\author{
RichaRd D. Howard \\ Department of Biological Sciences, Purdue University, West Lafayette, IN 47907 \\ AND \\ ARNOLD G. KLUGE \\ Museum of Zoology, and Division of Biological Sciences, \\ University of Michigan, Ann Arbor, MI 48109
}

\begin{abstract}
Observations and several types of field experiments on the mating behavior of wood frogs have revealed the proximate mechanisms for a size-related reproductive advantage in both males and females. For females, larger individuals produce larger clutches; for males, larger individuals can better remain clasped to females when contested by rival males and can better depose males clasped to other females. No results obtained support of the existence of mate choice in either males or females.

Males were estimated to be 4.74 times as variable as females in the number of zygotes produced per individual per season; however, much of the variation in male RS resulted from a male-biased sex ratio at the breeding site rather than from sexual selection. After taking sex ratio effects into consideration, males were estimated to be only 1.63 times as variable as females.

Patterns of variation in RS in males and females are associated with numerous sex-specific differences in life history and morphology. Life history differences include differential growth rates, ages at sexual maturity, and rates of mortality. Interpretation of how the body size dimorphism (females larger than males) in this species relates to sexual selection is consistent with information on how similar variations in body size influence RS for each sex, and how males and females differ in the functional relationship between body size and RS. Average RS increases more with body size in females than in males. Although body size directly influences RS for females, the possibility exists that, for males, other anatomical features correlated with body size more directly affect RS. Preliminary evidence suggests that sexual selection influences male arm length and that the male body size: RS relationship results as an incidental correlation.
\end{abstract}

Received May 14, 1984. Accepted November 16, 1984

A major goal of evolutionary biology is to document how specific processes effect patterns observed in nature. The process of sexual selection involves the interaction between variation in reproductive success (RS) and proximate mechanisms of mate choice and competition for mates to produce sexual differences in phenotypic attributes. Unfortunately, attempts to identify processes are limited by the particular research methods used, and our understanding of patterns can be significantly affected by the number and quality of studies on related taxa.

We report the results of a four year study on a local population of approximately 7,400 wood frogs, Rana sylvatica, in which we simultaneously observed the undisturbed mating behavior of about $90 \%$ of the individuals and used the re- mainder in controlled field experiments. This research was undertaken primarily to elucidate the proximate mechanisms responsible for an observed pattern of non-random mating (Howard, 1980; Berven, 1981). We also determined the amount of variation in RS (number of zygotes produced) for each sex and considered how the different means by which males and females maximize RS might be related to sex-specific differences in life history and morphology.

Wood frogs are classified as "explosive" breeders (Wells, 1977a): their mating period usually lasts less than one week, with most breeding occurring within 24 hr. Such extreme mating synchrony has been predicted to reduce variance in mating success among males, because one or a few individuals cannot physically monopolize a majority of breeding females 
(Trivers, 1972; Emlen and Oring, 1977), and to increase the likelihood that malemale competition will be exploitative rather than overtly aggressive (Wells, $1977 a$ ).

Choosing among alternative proximate mechanisms for both male-male competition and mate choice by females is aided by experimentation, because many factors can be controlled while investigating the importance of one or a few variables. However, such experimentation may entail creation of unrealistic, or at least evolutionarily novel, social and ecological conditions. Thus, experimental results can be difficult to interpret in terms of the natural situation. To identify any such experimental artifacts, we performed experiments in which all relevant variables were controlled and experiments in which only one variable was controlled. In addition, we made comparable observations on naturally breeding individuals.

All our observational and experimental results support the notion that malemale competition is a potentially important selective force in wood frogs. The possibility of mate choice by females is unsupported.

\section{Materials and Methods}

Our study of wood frogs took place during 1980-1983 in Saginaw Forest of the University of Michigan, 1.5 kilometers west of Ann Arbor. The frogs' breeding activity occurred in a semipermanent woodland pond with a surface area approximately $90 \times 50 \mathrm{~m}$ and a maximum depth of $1.5 \mathrm{~m}$. Overwintering sites were in the surrounding mixed evergreen and deciduous forest, particularly south of the pond. The pond was completely encircled by a $1 \mathrm{~m}$ high fence of $3.2 \mathrm{~mm}$ mesh galvanized hardware cloth, which allowed us to monitor accurately movements of frogs to and from the breeding environment. All individuals captured against the outside of the fence each spring were counted and sexed, and the body sizes (snout-ischium length) of most were recorded to the nearest 0.1 $\mathrm{mm}$. Estimates of survivorship and growth rate were obtained by recaptures of 364 of the 5,877 individuals which were given unique toe clips during 19801982. Only one individual from our population was recaptured in a sample of 680 individuals from a smaller population, $500 \mathrm{~m}$ north of the pond.

The one or two common oviposition sites that formed in the pond each spring were observed on a $24 \mathrm{hr}$ basis. Observations were taken from elevated painters' platforms to minimize disturbance. In 1981, the body sizes of 568 mated males and females were taken immediately after oviposition, and, each time a male mated successfully, a single strand of cotton thread was tied around his waist. Multiple waist bands provided evidence of polygyny, and these data provided the basis for estimating matings and reproductive success (see Appendix for a detailed calculation of these parameters). Periodic surveys in the study pond and the only other nearby breeding aggregation revealed no case in which a marked male mated away from the monitored egg deposition site. Females mated only once each season, and the reproductive success of that sex was estimated from the number of oviducal eggs in a sample of 110 individuals of known body size which were accidentally killed during the four years of study. Each clutch was dried and weighed, and the number of eggs/clutch was extrapolated from an egg number/ dry weight regression.

Several data analyses involved the use of body size categories. In all experiments, we recognized small, medium, and large males and females, which were $<37.5,37.6-41.5$, and $>41.6 \mathrm{~mm}$, respectively (males), and $<40.5,40.6-45.5$, and $>45.6 \mathrm{~mm}$, respectively (females). The limits of the small and large categories are approximately $1 \mathrm{SD}$ from the average body size recorded for each sex in $1980\left(N_{\text {males }}=1,607, N_{\text {females }}=1,227\right)$.

We conducted two types of field experiments: those in the pond, which involved the natural breeding population, and those which used $1.8 \mathrm{~m}$ diameter 
children's plastic swimming pools partially submerged in the pond. We refer to these as "pond release" and "pool" experiments, respectively. The pool experiment, first carried out in 1981 and replicated in 1982, considered how density and body size of competing males, and the sizes of the males and females in amplexus influenced the number of amplexed males displaced from their mates. No statistical difference was detected between years; thus, the data were treated as replicates. The density of competing males was a three-level factor-low, medium, and high $(15,30$, and 60 males/ pool, respectively). The density categories were comparable to those observed far from, near to, and at a wellestablished common oviposition site. Size of competing males was also a three-level factor-small, medium, and large. The third factor consisted of four categories: small male in amplexus $(x)$ with small female, small male $\times$ large female, large male $\times$ small female, large male $\times$ large female. Three pairs of frogs representing each of these categories were added to each pool. The pairs in each level were marked with the same color thread, stitched into the skin of the dorsal neck region, so that a male deposed from a female could be readily detected. The pool experiments ran $6.5 \mathrm{hr}$, which was the approximate average time it took an amplexed pair to reach the common oviposition site from the margin of the pond. The four pair-size combinations were created by placing males and females of the desired size combinations together in ice chests the night before the experiment was run.

Our analysis of sexual dimorphism in arm length (humerus + radioulna) utilized measurements taken from skeletons prepared from 133 males and $109 \mathrm{fe}$ males accidentally killed during the study. Urostyle and snout-vent lengths were significantly correlated in the two sexes $(r=0.77 ; P<0.001)$; however, we used urostyle length as the measure of body size in this analysis because it could be measured more accurately and it ex- plained significantly more of the variance in arm length than did snout-vent length.

Standard parametric and nonparametric statistical abbrevations are employed throughout the text. The Student-Newman-Keuls test was used to detect significant trends in the three factors used in the ANOVA.

\section{RESULTS}

\section{Life History and Reproductive Success}

During 1980-1983, the adult wood frog population at Saginaw Forest Pond varied from 5,202 to 8,955 individuals. In all years, the sex ratio of adults entering the pond was male-biased (range $=1.85-$ $4.00 \mathrm{males} / \mathrm{female}$; Fig. 1). Several demographic factors probably contributed to this bias: (1) Females had higher size-specific growth rates than males (ANCOVA: $F_{1,325}=550.18 ; P<0.001$; Fig. 2); however, despite a higher growth rate, most females became sexually mature one year later than males did (see also Berven [1981]). (2) Recapture of 122 of the 2,704 marked females and 242 of the 3,173 marked males indicated that yearly survival rate of females was lower than that of males $(8.0 \%$ vs. $12.5 \%$, respectively). Thus, lack of sexually immature females at the breeding site and higher mortality rates of females effected a male-biased breeding sex ratio.

Males and females also differed in time of arrival at the pond (Fig. 1). Individuals left their overwintering sites and entered the breeding pond during a period of $12-$ 30 days depending on weather conditions. Males typically preceded females into the pond, although considerable temporal overlap in arrival times occurred (Fig. 1). In addition, larger males often entered the pond earlier than smaller males $(r=-0.32, N=1,240, P<0.01$ in 1981; $r=-0.12, N=1,187, P<0.01$ in 1982). No significant relationship between body size and time of arrival existed for females.

Considerable variation occurred in female RS. Larger, older individuals pro- 

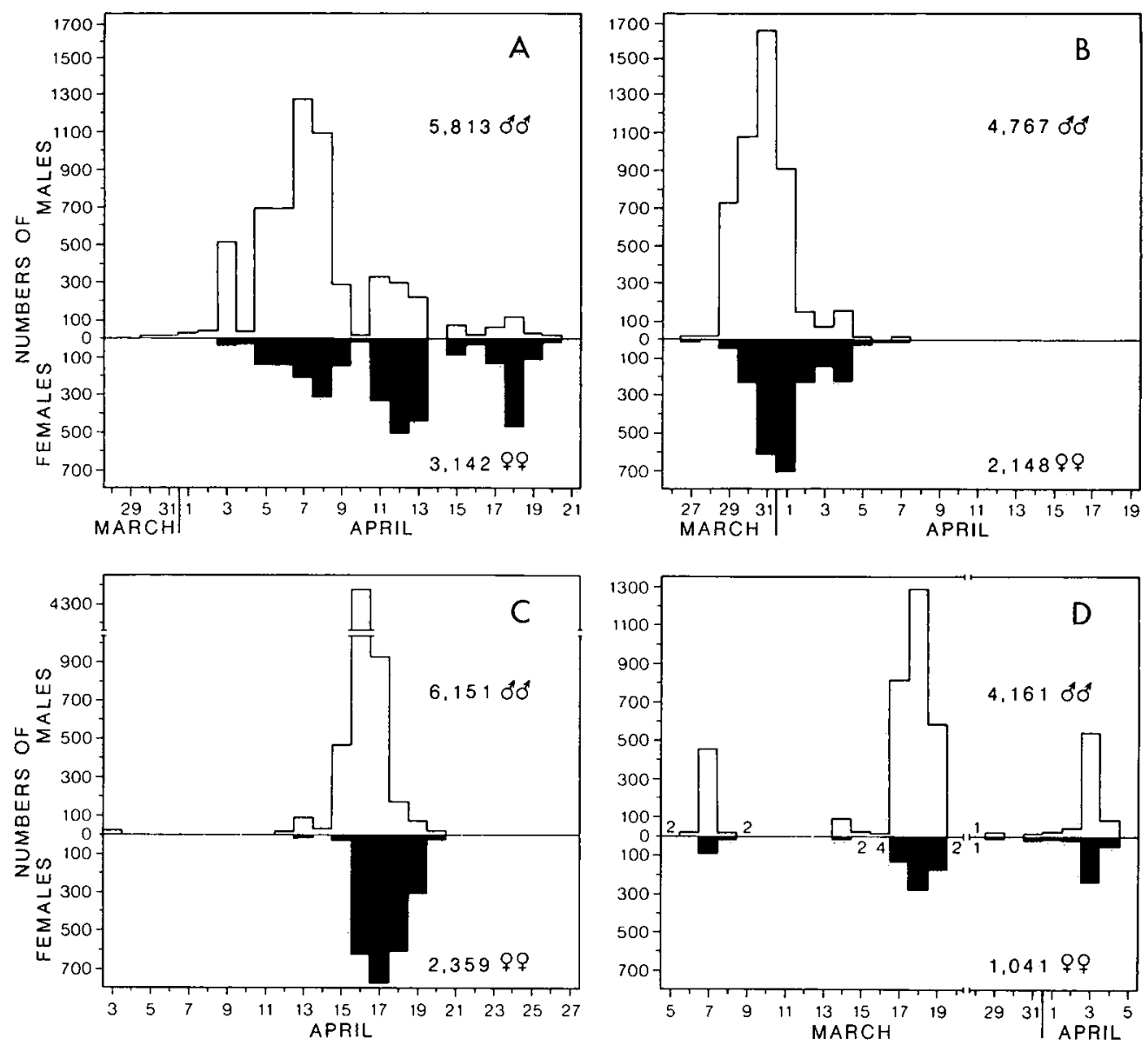

FIG. 1. Date of arrival of reproductively mature male and female wood frogs at Saginaw Pond. A. 1980. B. 1981. C. 1982. D. 1983 . Total numbers of males and females per year are listed to the right in each panel.

duced clutches that contained as much as five times the number of eggs as those of smaller, younger females $\left(R^{2}=0.61\right.$, $P<0.001, N=110$ females). The coefficient of variation (CV) in number of zygotes produced by these successfully breeding females was $28.91 \quad(\bar{x}=$ $599.68 \div \mathrm{SD}=173.38 \times 100$ ).

Approximately $61 \%$ of the males did not mate (see Appendix). Such lack of mating success resulted from the malebiased sex ratio and, to a lesser degree, the polygynous activity of a few males. The CV in number of matings obtained by males was 131.53 ; however, this measure is not comparable to that given above for females because the two estimates are based on different currencies, mates and zygotes (Howard, 1979, 1983). Estimates of the number of zygotes produced per male (see Appendix) resulted in a CV in $\mathrm{RS}$ of 137.06. The ratio of $\mathrm{CV}$ in zygote production for the sexes was 4.74 in favor of males (137.06/28.91).

As in other wood frog studies (Howard, 1980; Berven, 1981), male body size was correlated with mating success in our population. Based on a sample of 539 naturally breeding pairs in 1980, male size was significantly correlated with probability of mating $(r=0.66 ; P<0.05$; 12 male size categories were employed). 


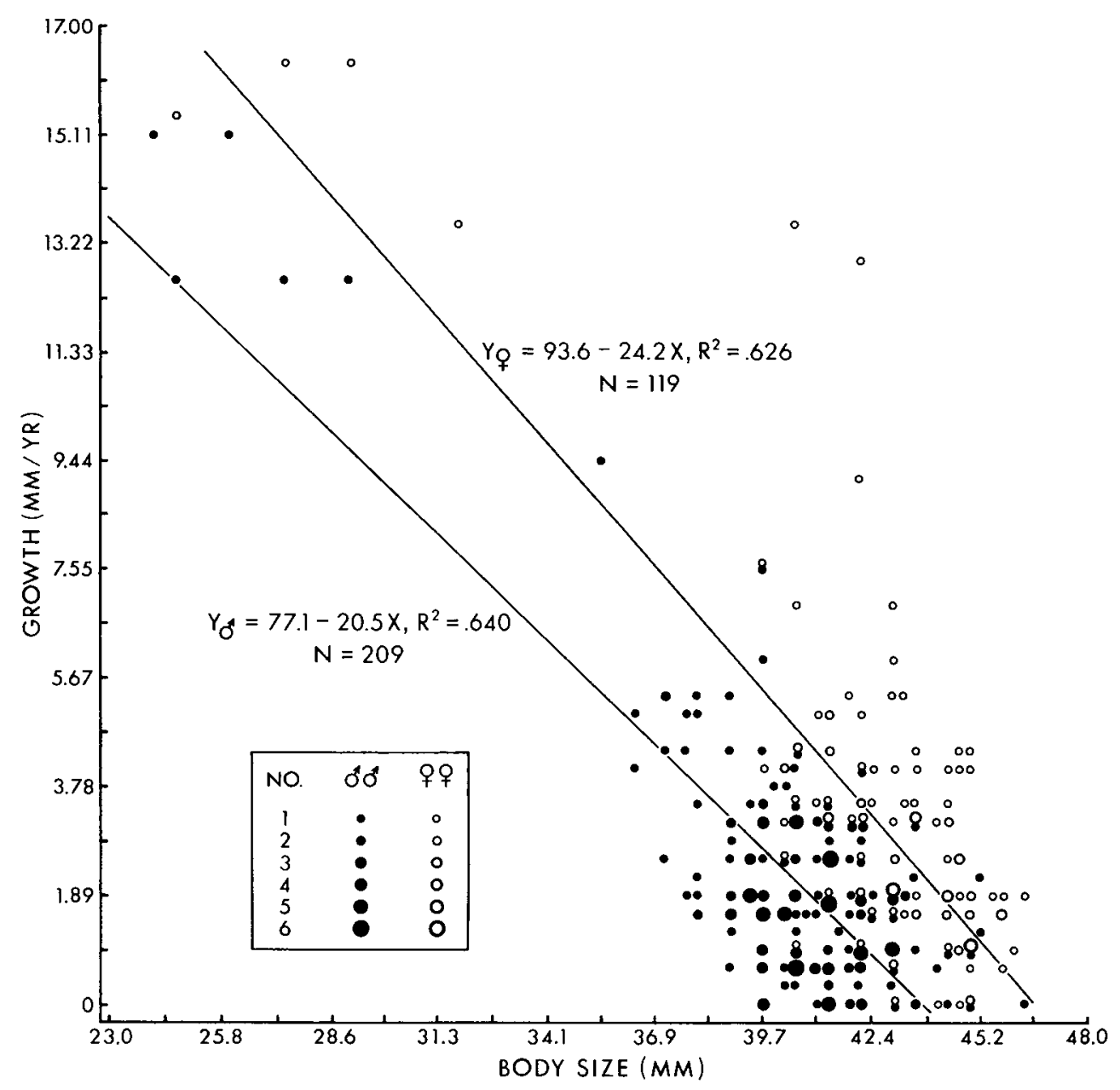

FIG. 2. Size-specific growth curves for wood frogs, 1980-1982. The regressions for males and females are based on log-body size. The differences in symbols are defined in the inset and the $x$ axis is on a log scale.

This trend was corroborated in 1981: larger males had a significantly greater chance of mating one or more times $(r=$ $0.53 ; P<0.05 ; 14$ male size categories) and of mating two or more times $(r=$ $0.68 ; P<0.05 ; 12$ male size categories). In addition, the slight tendency for positive size assortment in mated pairs (Fig. 3) means that larger males might also fertilize more eggs per mating.

Given that male and female RS were measured in the same currency, the relative influence of body size on variation in RS can also be assessed for the sexes.
Although RS increased with body size for each sex, the expected value of RS increased considerably more with size in females than in males (ANCOVA: $F_{1,24}=45.410, P<0.001$; Fig. 4). The regression lines differed significantly in slope $\left(F_{1,23}=24.948, P<0.001\right)$. In addition, variation in body size explained much more of the variation in average RS in females than in males, $R^{2}=0.946$ vs. 0.429 respectively. Although the relatively large amount of unexplained variation in male RS could be influenced by traits other than body size, it is also likely 
that chance is a very important factor. Given the male-biased sex ratio, 2,667 males $(57.6 \%$ of all males present; see Appendix) went unmated due solely to the rarity of females in 1981 . The effect of such a biased sex ratio can be roughly estimated by comparing the $\mathrm{CV}$ in male RS based on our sample of 568 matings with what could occur given a similar sample from a population with an equal sex ratio of breeding adults. In the hypothetical case, the polygynous activity of some males would result in a $\mathrm{CV}$ of 46.99 for number of zygotes produced (see Appendix). The male/female ratio of CV would be only 1.63 . Rough estimates of the relative importance of sexual selection and sex ratio bias suggest that $34 \%$ $(46.99 / 137.06)$ of the observed variation in number of zygotes/male is potentially due to sexual selection and $66 \%(90.07 /$ 137.06) of the variation could result from the male-biased sex ratio.

\section{Proximate Mechanisms: Pool Experiments}

We initiated several experiments to ascertain the proximate mechanisms that influenced differential RS among males. The possibility of female preference for larger males was tested by releasing females into fenced pens in the pond which contained marked males of various sizes, and into regions of the pond containing unmarked males. Results were unambiguous: the slightest movement by females resulted in their immediate amplexus by the nearest male. Thus, if females ever attempted to select particular males as mates, they would rarely be successful. Based on these experiments and some direct observations of free ranging females we concluded that initial pairing was random with respect to male body size and that the observed differential success of larger males occurred after the first pairing. We also conducted two experiments to detect female mate choice after pair formation, but we found no evidence of this in either case (see below).

In contrast to female choice, we commonly observed unpaired males attack-

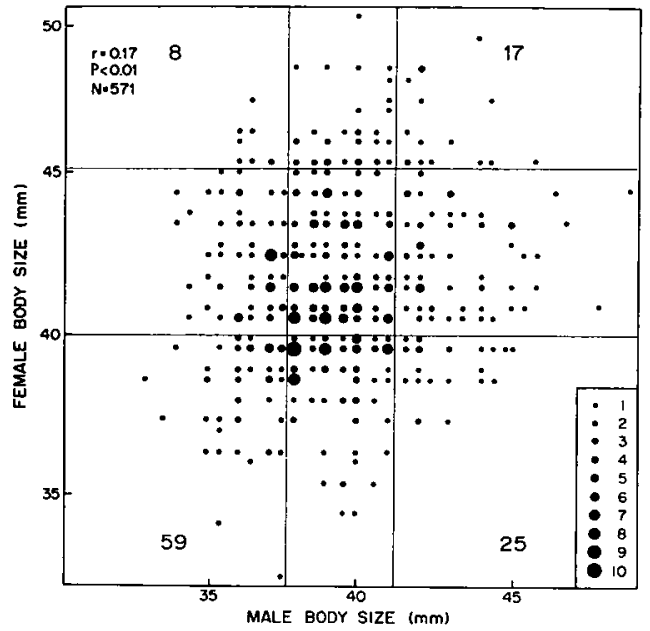

FIG. 3. Body sizes of male and female wood frogs that were observed to have mated together. Symbol size indicates number of pairs as defined in the inset. The two horizontal and two vertical lines delimit small, medium, and large body size categories of females and males, respectively. These were the body size classes used in the pool and pond release experiments discussed in the text (see also Fig. 6 and Tables 1 and 2). The number of pairs in the four size categories differed from expected values $\left(\chi^{2}=11.89 ; P<0.001\right)$. In particular, fewer small male $\times$ large female pairs were observed than predicted.

ing amplexed pairs and, sometimes, deposing amplexed males (Fig. 5). We conducted the pool experiments to determine whether males of different sizes were equally successful at remaining amplexed to females when potentially competing males were present. We controlled the size of males and females in amplexus, and the size and density of competing males. Results indicated that not all pairing combinations were equally stable (Table 1). In particular, small males paired with large females were more easily deposed than were males of any other pair-size category (Fig. 6A); more males amplexed to females were deposed in the presence of large competing males than in the presence of small or medium-sized competing males (Fig. 6B); and more males amplexed to females were deposed when competing males were in high density than in low or intermediate density 


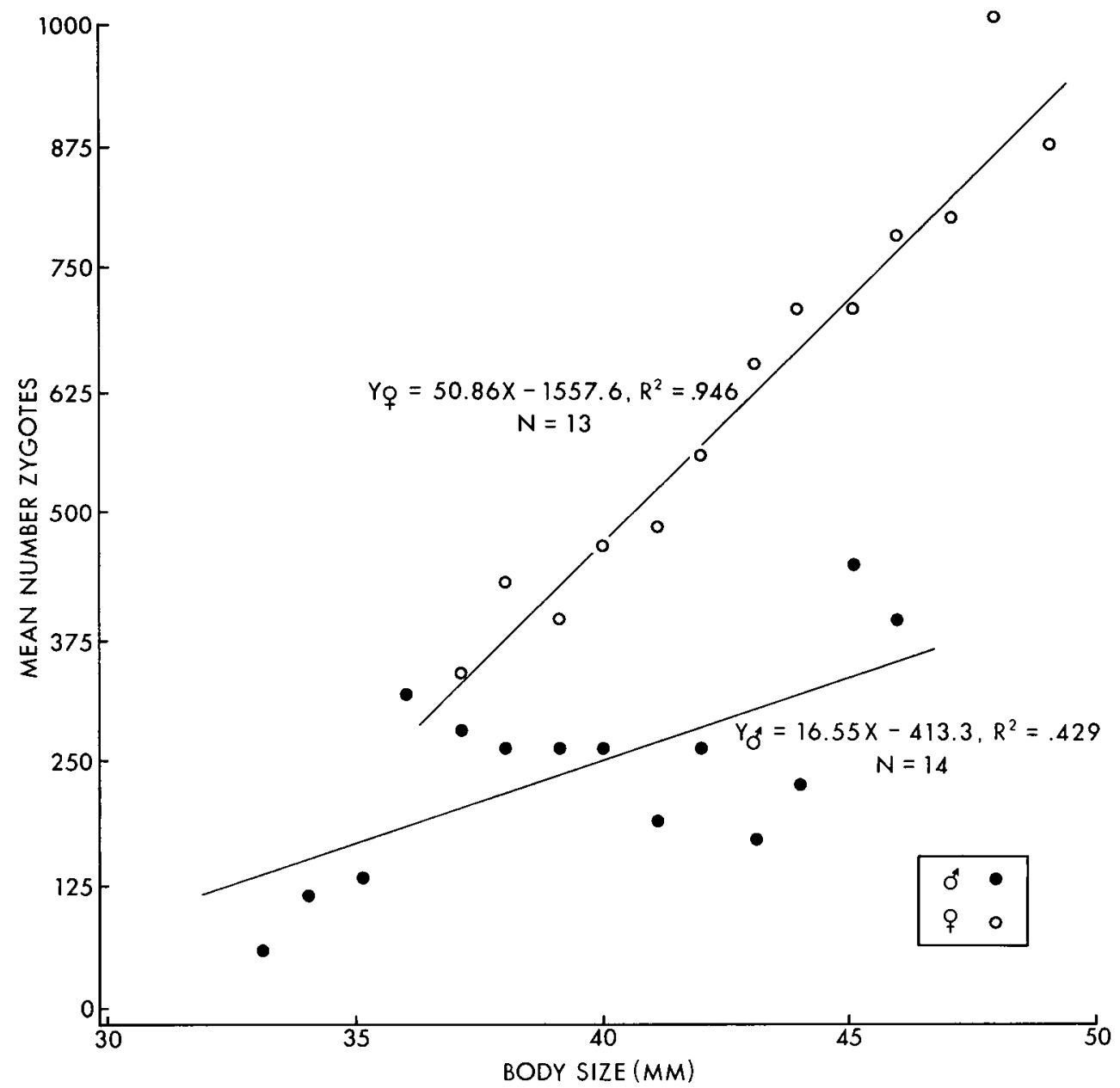

FIG. 4. Expected values for the number of wood frog zygotes produced (females) or sired (males) as a function of body size. Extreme values of body size were usually lumped into a single category to increase sample size: for males, $\leq 33 \mathrm{~mm}, \geq 46 \mathrm{~mm}$; for females, $>49 \mathrm{~mm}$.

(Fig. 6C). None of the interaction terms in the ANOVA was statistically significant (Table 1); however, more than two replicates of the experiment may be required to detect trends.

Results from the pool experiments can be correlated with observations on the breeding behavior of free-ranging wood frogs. Partitioning the mating success data obtained in 1981 on naturally breeding individuals into the four pair-size combinations used in the pool experiments reveals that the frequencies of the four combinations were unequal (Fig. 3). In particular, fewer pairs of the small male $\times$ large female category were obtained than one would expect at random.

To determine whether the behavior of amplexed females affected the chance that their male suitor would be deposed, we monitored pairs of the four pair-size combinations in all nine treatments during the 1982 pool experiment. Females in the four pair-size categories did not differ with respect to the number of times they moved toward a nearby competing male (i.e., a potential deposer of their suitor; ANOVA: $F_{3.32}=1.00 ; P=0.41$ ), 

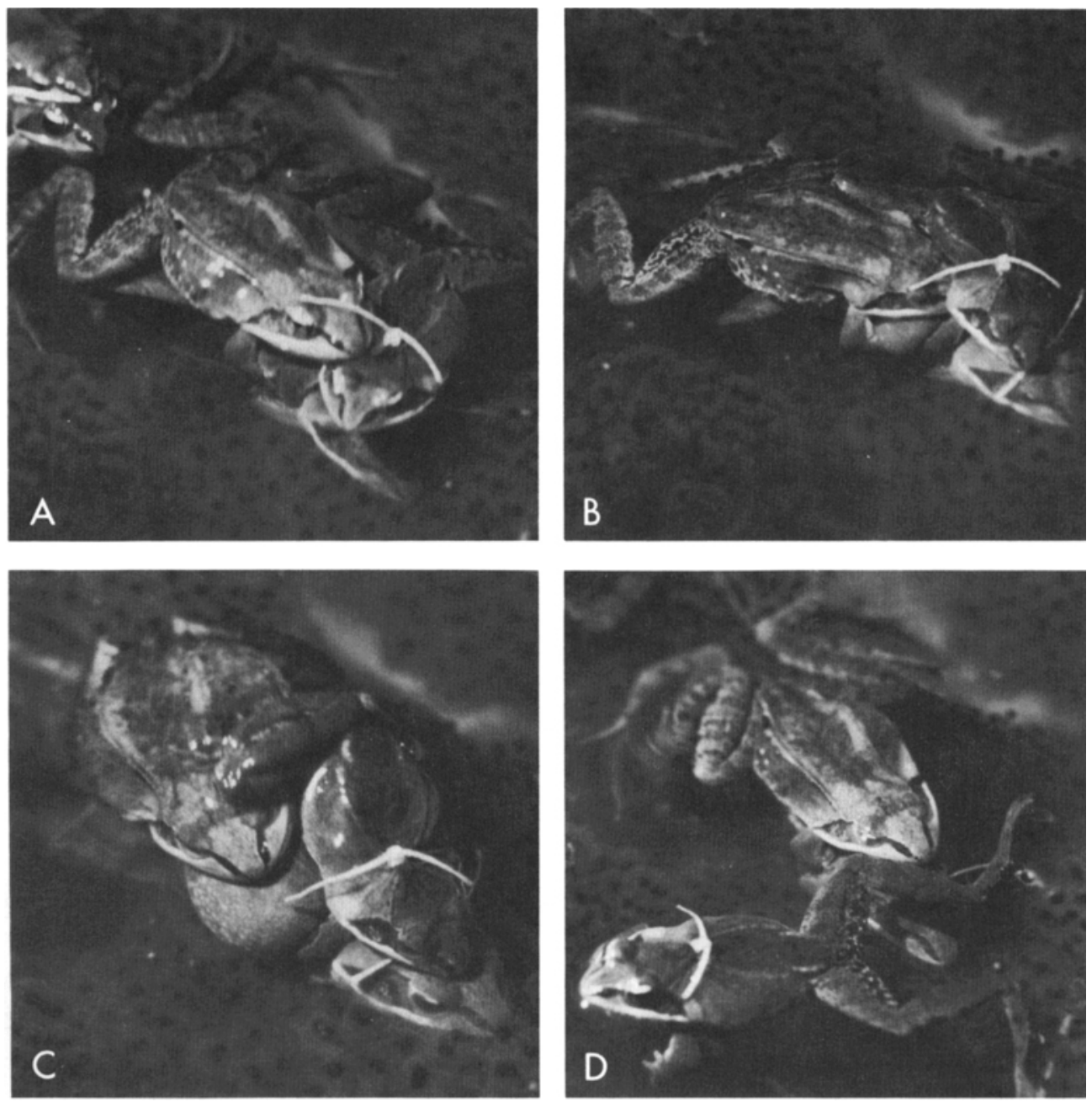

FIG. 5. An example of male-male competition in wood frogs. A small male, identified by the thread tied to its dorsum, is amplexed to a large female, in the usual anuran axillary embrace. A. The pair is present at the common oviposition site (note egg masses) but has yet to begin egg laying; a large male has amplexed the female in the inguinal region. B-C. The large male shifts to an axillary embrace. D. The small male is deposed from the female.

the number of times they moved away from a contesting male $\left(F_{3,32}=1.04 ; P=\right.$ 0.39 ), or the number of contests in which they were involved $\left(F_{3,32}=0.88 ; P=\right.$ 0.46).

\section{Proximate Mechanisms: Pond Release Experiments}

Additional agreement between naturally breeding individuals and pool experiments was obtained in 1982 and 1983 when pairs of all four size combinations were simultaneously released in the pond (Table 2). After release, the common egg deposition site was monitored for $24 \mathrm{hr}$ to determine whether the four size combinations were equally stable. Pairs began egg deposition, on average, $6.3 \mathrm{hr}$ after release (range $=0.63-25.35 \mathrm{hr}$; 1982). About $21 \%$ of the original males were deposed before their female's arrival at the egg deposition site. Once again, 

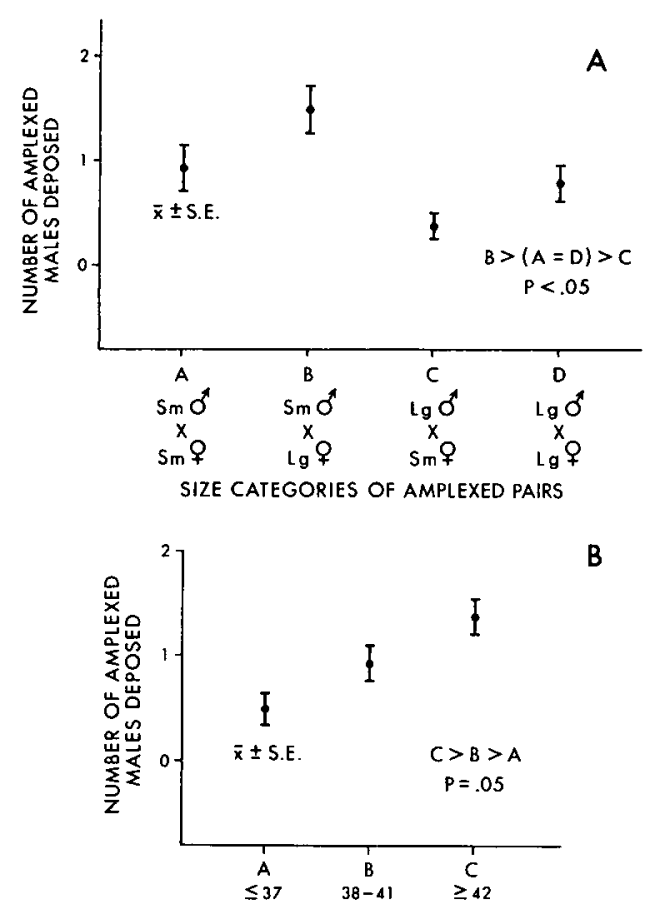

BODY SIZE OF COMPETING MALES(MM)

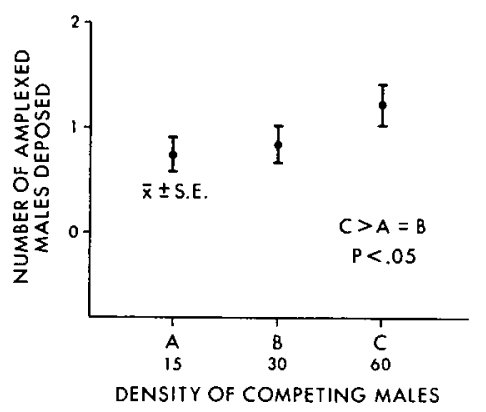

FIG. 6. Graphical descriptions of the main effects in the three-way ANOVA comparing number of male wood frogs deposed from their respective females (see Table 1), 1981-1982. A. The four pairsize categories. B. Size of competing males. C. Density of competing males. Means compared using the Student-Newman-Keuls test.

we observed significantly fewer small males amplexed to larger females successfully mating relative to the other three pair-size combinations.

In general, fewer males of any pair-size combination were deposed in the pond release experiments than in the pool experiments. The degree of male-male competition appears to have been greater in the pools, perhaps as a result of confinement or because $64 \%$ of the pairs released in the pond completed egg deposition in less time than the $6.5 \mathrm{hr}$ allotted to the pool experiments. However, despite these differences in magnitude, similar trends were observed in the pond release and pool experiments.

The pond release experiments were also used to test for the possibility of female choice because females that attempted to rid themselves of smaller amplexed males were predicted to take longer, on average, to reach the common egg deposition site; however, no differences were observed in average time of arrival at the egg deposition site among the four pair-size combinations $\left(F_{3,127}=0.84 ; P=0.47\right)$. Finally, pairs of the four pair-size combinations were released into experimental pools in the absence of male competitors to determine whether the females themselves would dislodge unwanted suitors. After $6.5 \mathrm{hr}$, all males remained firmly clasped to their original mates.

\section{An Alternative Hypothesis}

Visual inspection of amplexed pairs led us to predict that a male's arm length could influence his ability to remain clasped to females when contested by other males. In the extreme case, small males cannot encompass the chest of large females and may be particularly vulnerable to the prying actions of rival males (Fig. 5). The possibility of longer arm length providing reproductive advantages is consistent with the observed correlation between male body size and RS because larger males possess longer arms $\left(R^{2}=0.799, P<0.001, N=133\right.$; Fig. 7).

Preliminary support for the arm length hypothesis would be obtained if the allometric relationship between arm length and body size differs between the sexes; that is, assuming no advantage of longer arms in females, we expect males to have longer arms than females at every body size. As we predicted, males have signif- 
TABLE 1. ANOVA table comparing average number of male wood frogs deposed from their females (see text).

\begin{tabular}{lrrrrl}
\hline \multicolumn{1}{c}{ Source of variation } & \multicolumn{1}{c}{ SS } & d.f. & MS & \multicolumn{1}{c}{$F$} & $P$ \\
\hline Main Effects & 23.21 & 7 & 3.32 & 8.23 & 0.001 \\
1. Pair-size categories & 11.15 & 3 & 3.72 & 9.23 & 0.001 \\
2. Size of competing males & 9.19 & 2 & 4.60 & 11.41 & 0.001 \\
3. Density of competing males & 2.86 & 2 & 1.43 & 3.55 & 0.039 \\
Two-way Interactions & 9.67 & 16 & 0.60 & 1.50 & 0.154 n.s. \\
$1 \times 2$ & 4.14 & 6 & 0.69 & 1.71 & 0.146 n.s. \\
$1 \times 3$ & 4.81 & 6 & 0.80 & 1.99 & 0.093 n.s. \\
$2 \times 3$ & 0.72 & 4 & 0.18 & 0.45 & 0.773 n.s. \\
Three-way Interaction & & & & & \\
$1 \times 2 \times 3$ & 7.28 & 12 & 0.61 & 1.51 & 0.167 n.s. \\
Explained & 40.15 & 35 & 1.15 & 2.85 & 0.001. \\
Residual & 14.50 & 36 & 0.40 & & \\
Total & 54.65 & 71 & 0.77 & & \\
\hline
\end{tabular}

icantly longer arms than females of the same size (ANOCOVA: $F_{1,239}=119.54$, $P<0.001$; Fig. 7). The regression equations for the sexes differed significantly in slope $\left(F_{1,238}=5.28, P=0.023\right)$.

\section{Discussion}

\section{Non-Random Mating in Anurans}

Non-random mating patterns have now been clearly demonstrated for at least 22 out of 30 species of anurans (Table 3). Trends are unclear for four species because each includes populations that mate randomly as well as non-randomly. Four

TABLE 2. Number of male wood frogs in the four pair-size categories that were deposed in the pond release experiment. Within each block, number in upper left refers to 1982 data, lower right refers to 1983 data; central numbers combine data for both years. More small males paired to large females were deposed relative to other categories $\left(\chi^{2}=42.6\right.$; $P<0.001$; combined data).

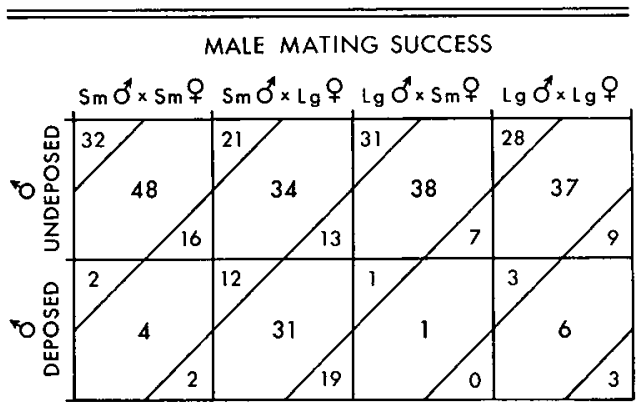

other species appear to mate at random, at least with respect to the particular male traits considered. Unfortunately, this typically means random relative to male body size, because size can be measured easily and is likely to influence RS. Whether or not male traits other than size contribute to non-random mating patterns is largely unknown (but see Ryan, $1980 a$ ). The operation of male-male competition and/or female choice in the non-randomly mating species is usually inferred from observational data; only in a few cases have investigators conducted field or laboratory experiments to distinguish more clearly among alternative hypotheses. An additional complication is that, too often, conclusions concerning the relative importance of the two processes of sexual selection are based on two commonly observed and easily recorded outcomes: size dependent mating success and size assortative mating. As pointed out by Arak (1983b), these outcomes can be consistent with, but not unambiguous evidence for, both malemale competition and female choice. Necessary and sufficient conditions for documenting male-male competition as a selective force must involve some measurement of the processes and their outcomes: for example, differential and repeatable success of particular males (or classes of males) in male-male interac- 


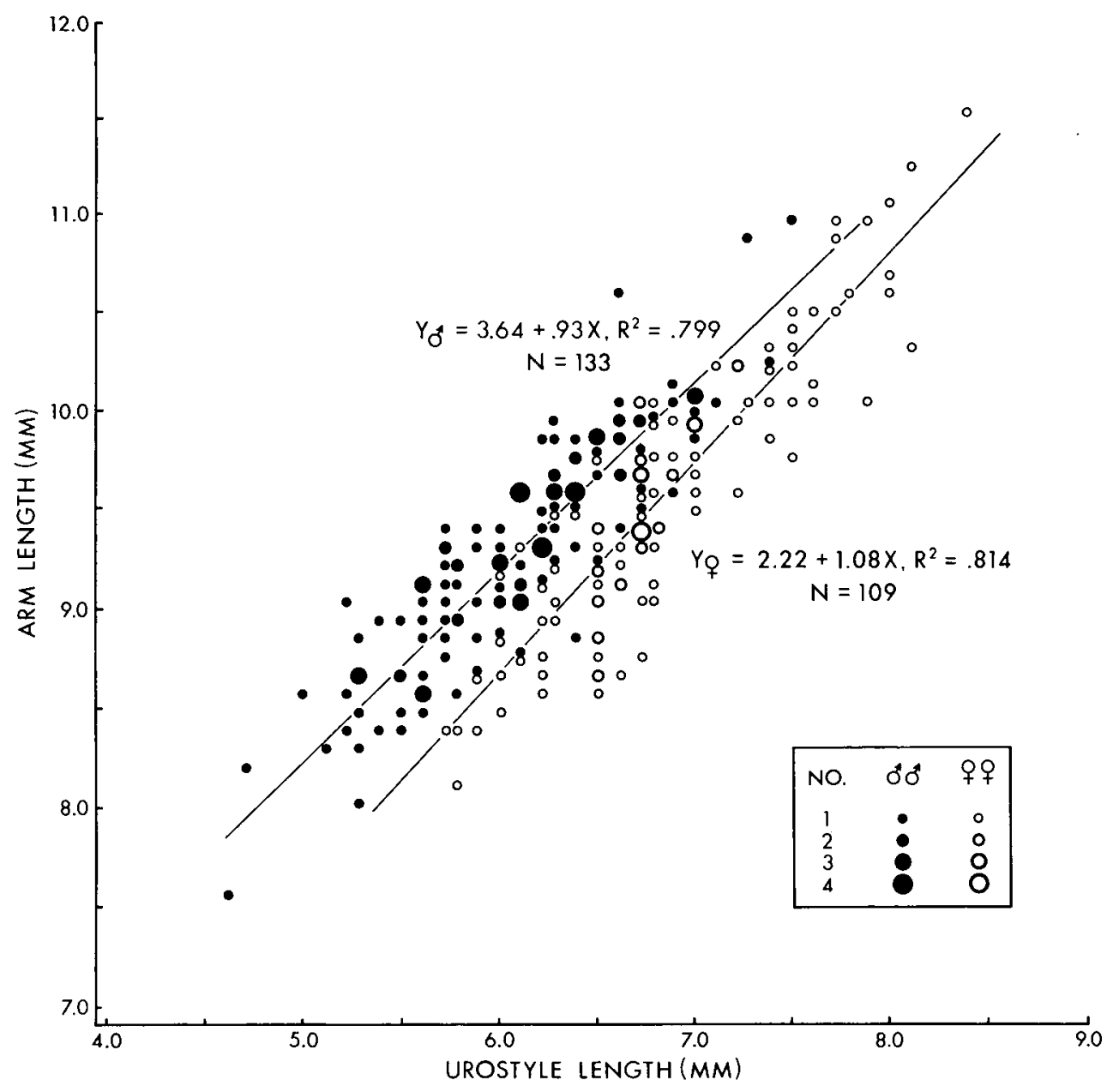

FIG. 7. The correlation between arm length and urostyle length in male and female wood frogs from Saginaw Pond. Differences in symbols are defined in inset.

tions, as well as a recognizable reproductive benefit for winners in male-male encounters. Similarly, documentation that mate choice by females is adaptive should require demonstrating that females select particular males (or classes of males) as mates and actively reject other males, as well as showing that some reproductive benefit accrues to discriminating females (see also Halliday, 1983; Parker, 1983). Several authors have recently suggested that non-random female mating preferences may be neutral with respect to female $\mathrm{RS}$ in species in which males provide no parental investment in young
(Lande, 1980; Kirkpatrick, 1982; Arnold, 1983). However, this prediction largely results because female RS is defined solely on the basis of zygote production, not on the subsequent success of the zygotes produced. Earlier theories of mate choice did not require that discriminating females produce more $z y-$ gotes than randomly mating females, but only that the sons of discriminating females obtained some mating advantage (e.g., Fisher, 1958; Trivers, 1972).

Our investigation demonstrates nonrandom mating in a wood frog population. All observations and experiments 
TABLE 3. Evidence for non-random mating and components of sexual selection.

\begin{tabular}{|c|c|c|c|c|c|c|c|c|}
\hline Genus & Species & Study & $\begin{array}{c}\text { Mating } \\
\text { ran- } \\
\text { dom } 1 \\
\end{array}$ & $\begin{array}{l}\text { Mating } \\
\text { non- } \\
\text { random }\end{array}$ & $\begin{array}{c}\text { Male- } \\
\text { male } \\
\text { compe- } \\
\text { tition } \\
\text { impli- } \\
\text { cated }\end{array}$ & $\begin{array}{c}\text { Male- } \\
\text { male } \\
\text { compe- } \\
\text { tition } \\
\text { demon- } \\
\text { strated } \\
\end{array}$ & $\begin{array}{c}\text { Female } \\
\text { choice } \\
\text { - impli- } \\
\text { cated } \\
\end{array}$ & $\begin{array}{l}\text { Female } \\
\text { choice } \\
\text { demon- } \\
\text { strated }\end{array}$ \\
\hline \multirow[t]{4}{*}{ Bufo } & americanus & Licht, 1976 & & $x$ & & & $x$ & \\
\hline & & Gatz, $1981 a$ & & $x$ & $x$ & & & \\
\hline & & Wilbur et al., 1978 & $x$ & & & & & \\
\hline & & Kruse, 1981 & $x$ & & & & & \\
\hline Bufo & bufo & Davies and Halliday, 1979 & & $x$ & & $x$ & & \\
\hline Bufo & calamita & Arak, $1983 a$ & & $x$ & & $x$ & & \\
\hline Bufo & canorus & Kagarise Sherman, 1980 & & $x$ & & $x$ & $x$ & \\
\hline Bufo & cognatus & Sullivan, $1982 a, 1982 b$ & & $x$ & & & $x$ & \\
\hline Bufo & exsul & Kagarise Sherman, 1980 & & $x$ & & $x$ & & \\
\hline Bufo & fowleri & Fairchild, 1981 & & $x$ & & & $x$ & \\
\hline Bufo & quercicus & Wilbur et al., 1978 & & $x$ & & & $x$ & \\
\hline Bufo & terrestris & Wilbur et al., 1978 & $x$ & & & & & \\
\hline Bufo & typhonius & Wells, 1979 & & $x$ & & $x$ & & \\
\hline \multirow[t]{2}{*}{ Bufo } & woodhousei & Sullivan, $1982 c, 1983$ & & $x$ & $x$ & & $x$ & \\
\hline & & Woodward, 1982 & & $x$ & & & & \\
\hline Centrolenella & colymbiphyllum & McDiarmid, 1978 & & $x$ & & & & \\
\hline Centrolenella & fleischmanni & Greer and Wells, 1980 & & $x$ & & & $x$ & \\
\hline Centrolenella & valerioi & McDiarmid, 1978 & & $x$ & & & & \\
\hline Hyla & chrysoscelis & Godwin and Roble, 1983 & $x$ & & & & & \\
\hline Hyla & cinerea & Gerhardt, 1982 & $x$ & & & & & \\
\hline Hyla & crucifer & Gatz, $1981 b$ & & $x$ & & & & \\
\hline Hyla & marmorata & Lee and Crump, 1981 & & $x$ & & & & \\
\hline Hyla & regilla & $\begin{array}{l}\text { Whitney and Krebs, } \\
1975 a 1975 b\end{array}$ & & $x$ & & & $x$ & \\
\hline Hyla & rosenbergi & Kluge, 1981 & & $x$ & & $x$ & & $x$ \\
\hline \multirow[t]{2}{*}{ Hyla } & versicolor & Fellers, $1979 a, 1979 b$ & $x$ & & & & & \\
\hline & & Gatz, $1981 b$ & & $x$ & $x$ & & $x$ & \\
\hline Physalaemus & pustulosus & Ryan, $1980 a, 1983$ & & $x$ & & & & $x$ \\
\hline \multirow[t]{2}{*}{ Rana } & catesbeiana & Howard, 1978 & & $x$ & & $x$ & & $x$ \\
\hline & & Emlen, 1976; Ryan, $1980 b$ & & $x$ & $x$ & & $x$ & \\
\hline Rana & clamitans & Wells, $1977 b ; 1978$ & & $x$ & & $x$ & $x$ & \\
\hline \multirow[t]{2}{*}{ Rana } & sylvatica & Howard, 1980; & & $x$ & $x$ & & $x$ & \\
\hline & & Berven, 1981 & & $x$ & & $x$ & $x^{4}$ & \\
\hline \multirow[t]{2}{*}{ Rana } & temporaria & Savage, 1961 & & $x$ & & & & \\
\hline & & Arak, $1983 b$; Halliday, 1983 & & $x$ & $x$ & & & \\
\hline Triprion & petasatus & Lee and Crump, 1981 & & $x$ & & & & \\
\hline Scaphiopus & bombifrons & Woodward, 1982 & $x$ & & & & & \\
\hline Scaphiopus & couchi & Woodward, 1982 & $x^{2}$ & $x$ & & & & \\
\hline Scaphiopus & multiplicatus & Woodward, 1982 & $x^{3}$ & $x$ & & & & \\
\hline
\end{tabular}

I Random relative to any phenotypic trait considered. which was usually body sizc.

23 of 4 populations sampled.

31 of 2 populations sampled.

4 Male choice.

conducted support the existence of malemale competition but provide no evidence for female choice. In particular, relative to smaller males, larger males are better at remaining clasped to females and in deposing males amplexed to other females. As a result, larger males obtained a significant mating advantage. These results greatly clarify an earlier study (Howard, 1980) and agree with reports on another wood frog population (Berven, 1981).

In our pond release experiments, the four most extreme pair-size combinations were made equally common artificially; however, the frequency of these combinations became decidedly nonrandom by the time of egg deposition. 
These findings call into question the accuracy of detecting non-random mating, or the degree of non-random mating, by the commonly used technique of collecting amplexed pairs haphazardly in the breeding habitat (e.g., Wilbur et al., 1978; Lee and Crump, 1981; Gatz, 1981b). Typically, investigators who use this method compare the body size of paired males with unpaired males in the same population to determine the existence of a male size advantage. Not only is the true mating status of an "unpaired" male unclear, the entire process of male-male competition or mate choice does not end for any particular amplexed pair until egg deposition (see also Verrell, 1983). Thus, such studies might be expected to underestimate consistently the degree of non-random mating and of sexual selection.

In an excellent study on another wood frog population, which utilized field observations and laboratory experimentation, Berven (1981) suggested that male wood frogs exercised mate choice by preferring larger females. No such phenomenon was observed in our population. In fact, the most stable pair-size combination in both our experiments and observations of naturally breeding pairs was large males paired to small females (Fig. 6A). The ecological and social conditions that might make male mate choice likely are unclear. Also, Berven's (1981) report of a female-biased sex ratio in several of the ponds he studied appears to represent a unique finding in this species (Banta, 1914; Wright, 1914; Howard, 1980; this study).

Unlike earlier investigations on wood frogs (Howard, 1980; Berven, 1981), a slight positive size assortment existed for successfully mated pairs in the population we studied (Fig. 3). Given the large amount of variation present in our sample of 571 individuals, a similar tendency would be difficult to discern in smaller samples. In addition, given the effect of male density on frequency of amplexed males deposed (Fig. 6C) and the tendency for small males to be more sensitive to male-male competition (Fig. 6A), size assortment may only occur under high population densities. A similar density effect has been suggested for Rana temporaria (Arak, 1983b), a European species that closely resembles wood frogs in ecology and behavior. The size assortment observed in our study was consistent with experimental results on male-male competition; in particular, small males paired to large females occurred less frequently than expected. Such size assortative mating has been proposed as a means to ensure high fertilization success in some species of anurans (Licht, 1975; Davies and Halliday, 1977) but it confers no such benefit in other species (e.g., Howard, 1978; Kruse, 1981). We could also detect no such advantage in wood frogs. Despite considerable variation in relative sizes of mated pairs, a random sample of $13 \mathrm{egg}$ masses deposited by pairs of unknown size revealed no instance in which less than approximately $97 \%$ of the eggs were fertilized (see also Seigel, 1983).

\section{Sexual Selection and Sex Ratios}

Synchronous mating by females in a population has been predicted to affect the form and intensity of male-male competition and female choice in all species (Trivers, 1972; Wells, 1977a; Emlen and Oring, 1977; Parker, 1983). Although mating synchrony is a definite factor in the wood frog mating system (Howard, 1980; Berven, 1981), the effects of a male-biased sex ratio must also be considered. Preponderance of males should increase both male-male competition for the relatively scarce females and the likelihood of female choice due to the reduction in time and energy spent locating a large number of males when searching for a suitable mate (Parker, 1983).

Emlen and Oring (1977) suggest that the operational sex ratio (OSR), the ratio of the number of adult males to the number of receptive females at any point in time, estimates the intensity of sexual selection. This measure has several potential methodological pitfalls (Kluge, 1981 
p. 135) and may be less useful in predicting selection intensity than are measures incorporating the amount of variation in RS (Wade, 1979; Wade and Arnold, 1980; Howard, 1983); however, the OSR should serve as a reasonable index of the intensity of male-male competition because it measures the scarcity of a limiting resource-females. In our population, we estimate that the OSR averaged 16:1 during peak mating activity in 1980 , and that the OSR was considerably higher in the vicinity of the egg deposition site. Species with more prolonged breeding seasons seem to have lower OSR values than those we observed for wood frogs. For example, the OSR for Hyla rosenbergi ranged from 6.9:1 to 9.3:1 (Kluge, 1981), and for Rana catesbeiana the OSR was 5.7:1 (Emlen, 1976). Presumably, the overall malebiased adult breeding sex ratio largely contributed to the relatively high OSR in wood frogs; overall adult breeding sex ratios in $H$. rosenbergi and $R$. catesbeiana were close to $1: 1$.

Although a high OSR may increase the likelihood of selection for mate choice by females, the tendency of males to grasp anything nearby that could be a female should reduce a female's ability to evaluate males without being clasped. In addition, the intense male-male competition for paired females could result in injury or death to females that attempt male choice after initial pairing. Proximate benefits of mate choice are not obvious. Males do not defend resources required by females. Potential long-term benefits include selection of mates with higher genetic quality as reflected by faster growth rate or greater ability to survive to old age (e.g., Trivers, 1972; Borgia, 1979; but see Lande, 1981; Kirkpatrick, 1982). While these benefits are possible in wood frogs, the relatively low variation in growth rate of similarly-sized males (Fig. 2) and their short lifespan, regardless of size, render these considerations unlikely.

Considerable variation exists within each sex in zygote production. Body size explains much more of this variation in females than males, $R^{2}=0.946$ vs. 0.429 , respectively. Much of the unexplained variation in male $R S$ could result from the male-biased sex ratio; that is, even in the absence of male-male competition and female choice, $57.6 \%$ of the males must go unmated. By contrast the effects of polygyny resulted in only $3.3 \%$ of the males going unmated (see Appendix). Sex ratio bias must produce a significant random component of the variation in male RS. But how large? A crude estimate predicts that it could account for as much as $66 \%$ of the total variation in male RS. Although this prediction is most probably an overestimate, it suggests that the remaining $57.1 \%$ of unexplained variation in male RS could easily be due to chance rather than unmeasured phenotypic traits. For this reason, we suspect that the relative variability in RS between the sexes potentially affecting sexual traits is much closer to 1.63 , the sex ratio-corrected estimate of male $\mathrm{CV} / \mathrm{fe}$ male $C V$, than to 4.74 , the $C V$ ratio obtained when sex ratio bias is not considered. Complications in comparing RS variation between the sexes have been noted by other authors (e.g., Payne and Payne, 1977) and have recently been incorporated into statistical estimates of male RS (Wade and Arnold, 1980). However, we suggest that before a sex ratio bias is considered as an aspect of sexual selection (e.g., Price, 1984), experiments should be performed that quantify how differences in overall sex ratio within a species influence relative variation in $R S$ between the sexes.

\section{Sexual Selection and Dimorphism}

Numerous investigators have reported that female wood frogs exceed males in body size (e.g., Wright and Wright, 1949; Bellis, 1961; Wells, 1978; Howard, 1980; Berven, 1981), as is typical of anuran species in which males do not engage in combat for mating territories or females (Wells, 1978; Shine, 1979; Woolbright, 1983). Similar results occurred in the 
our population: $\bar{x}$ female body size $=$ $42.86, \mathrm{SD}=3.28, N=539 ; \bar{x}$ male body size $=39.77 \mathrm{~mm}, \mathrm{SD}=2.33, N=1,598$. Relating the size dimorphism pattern of wood frogs to sexual selection requires several types of information for each sex including how body size influences survival (Lande, 1980), how RS varies with body size, and the functional relationship between body size and RS.

The functional relationship between female body size and RS is straightforward: variation in $\mathrm{RS}$ results from the volume of eggs that females can hold, and egg capacity increases directly with female size. The situation is more complex for males. Males employ numerous mating behaviors that could influence their RS. Our results suggest that large male size only increases their ability to remain clasped to females when paired and to depose males amplexed to other females. Variation in male body size may have little or no effect on performance of other male mating behaviors. Large male size may confer reproductive advantages by influencing overall strength needed in male-male competition. Alternatively, at least some of the observed effect of body size on RS might result from correlations between body size and other phenotypic characteristics that more directly affect RS.

Our arm length analysis suggests that the correlation between male body size and RS could be an incidental effect of the relationship between male size and arm length. However, this result is also consistent with several other hypotheses, and more supporting data are necessary before any firm conclusions can be reached. Data on the biomechanics of arms during amplexus and a comparative survey of other species might be especially revealing. Relative to the latter, we predict that sexual differences in the arm length-body size relationship should be more common in species like wood frogs in which males primarily compete for females that are already in amplexus. In species with male combat, overall strength (hence large body size) may con- tribute more to success in wrestling contests than clasping ability. As a result, males may be similar to females in arm length but may differ in other regards (e.g., diameter of arm bones, arm muscle bulk).

Many studies of anurans have reported male size advantages in reproduction (e.g., Wells, 1977b; Howard, 1978; Woodward, 1982; Ryan, 1983). Unfortunately, few if any phenotypic attributes were usually measured other than male size (but see Ryan, 1980a, 1983). The proximate mechanisms used by males to obtain mates often differ dramatically among species, and it is likely that various phenotypic characters correlated with male body size may affect reproductive success as much or more than body size itself. Future studies of sexual selection should include measurements of numerous male and female characteristics that can be predicted to influence RS, as well as measurements of reproductive parameters (Arnold and Wade, 1984). Only in this manner can specific hypotheses be tested concerning the phenotypic consequences of sexual selection.

\section{ACKNOWLEDGMENTS}

We thank the many University of Michigan graduate and undergraduate students who worked on this project. Particularly helpful were Owen Ballow, Steve Dobson, Randy Evans, Susan Finger, Dennis Harris, Jean Kluge, John Kluge, Fred Kraus, Vicki LaRoche, Andrea Linder, Amy Lowichik, Liz McGhee, Chris Richards, Maria Salgado, and Pete Tolson. We thank S. J. Arnold, S. Dobson, M. Kirkpatrick, C. Kagarise Sherman, and $\mathrm{K}$. Wells for their helpful comments on earlier drafts of this paper. We wish to acknowledge the School of Natural Resources for generously making the University of Michigan's Saginaw Forest Preserve available to us, and Margaret Van Bolt who drafted all of the art work. The research could not have been undertaken without financial aid from the National Science Foundation, DEB7922123 (to Arnold G. Kluge). 


\section{Literature Cited}

ARAK, A. 1983a. Sexual selection by male-male competition in natterjack toad choruses. Nature 306:261-262.

- 1983b. Male-male competition and mate choice in anuran amphibians, pp. 181-210. In P. Bateson (ed.), Mate Choice. Cambridge Univ. Press, Cambridge, U.K.

ARNOLD, S. J. 1983. Sexual selection: the interface of theory and empiricism, pp. 67-107. In P. Bateson (ed.), Mate Choice. Cambridge Univ. Press, Cambridge, U.K.

Arnold, S. J., AND M. J. Wade. 1984. On the measurement of natural and sexual selection: applications. Evolution 38:720-734.

BANTA, A. M. 1914. Sex recognition and the mating behavior of the wood frog, Rana sylvatica. Biol. Bull. 26:171-183.

Bellis, E. D. 1961. Growth of the wood frog, Rana sylvatica. Copeia 1961:74-77.

Berven, K. A. 1981. Mate choice in the wood frog, Rana sylvatica. Evolution 35:707-722.

Borgia, G. 1979. Sexual selection and the evolution of mating systems, pp. 19-80. In M. S. Blum and N. A. Blum (eds.), Sexual Selection and Reproductive Competition in Insects. Academic Press, N.Y.

Davies, N. B., AND T. R. Halliday. 1977. Optimal mate selection in the toad Bufo bufo. Nature 269:56-58.

-1979. Competitive mate searching in male common toads, Bufo bufo. Anim. Behav. 27: 1253-1267.

EMLEN, S. T. 1976. Lek organization and mating strategies in the bullfrog. Behav. Ecol. Sociobiol. 1:283-313.

EmLen, S. T., ANd L. W. ORing. 1977. Ecology, sexual selection, and the evolution of mating systems. Science 197:215-223.

FAIRCHILD, L. 1981. Mate selection and behavioral thermoregulation in Fowler's toads. Science 212:950-952.

Fellers, G. M. 1979a. Aggression, territoriality, and mating behaviour in North American treefrogs. Anim. Behav. 27:107-1 19.

- $1979 b$. Mate selection in the gray treefrog, Hyla versicolor. Copeia 1979:286-290.

FisHER, R. A. 1958. The Genetical Theory of Natural Selection, 2nd ed. Dover, N.Y.

Gatz, A. J. 1981a. Non-random mating by size in American toads, Bufo americanus. Anim. Behav. 29:1004-1012.

- $1981 \mathrm{~b}$. Size selective mating in Hyla versicolor and Hyla crucifer. J. Herpetol. 15:114116.

Gerhardt, H. C. 1982. Sound pattern recognition in some North American treefrogs (Anura: Hylidae): Implications for mate choice. Amer. Zool. 22:581-595.

Godwin, G. J., AND S. M. Roble. 1983. Mating success in male treefrogs, Hyla chrysoscelis (Anura: Hylidae). Herpetologica 39:141-146.

Greer, B., AND K. D. Wells. 1980. Territorial and reproductive behavior of the tropical American frog, Centrolenella fleischmanni. Herpetologica $36: 318-326$.

Halliday, T. R. 1983. Do frogs and toads choose their mates? Nature 306:226-227.

HowARD, R. D. 1978. The evolution of mating strategies in bullfrogs, Rana catesbeiana. Evolution 32:850-871.

- 1979. Estimating reproductive success in natural populations. Amer. Natur. 114:221-231. - 1980. Mating behaviour and mating success in wood frogs, Rana sylvatica. Anim. Behav. 28:705-716.

- 1983. Sexual selection and variation in reproductive success in a long-lived organism. Amer. Natur. 122:301-325.

Kagarise Sherman, C. 1980. A comparison of the natural history and mating system of two anurans: Yosemite toads (Bufo canorus) and black toads (Bufo exsul). Ph.D. Diss., Univ. Michigan, Ann Arbor, MI.

KIRKPATRICK, M. 1982. Sexual selection and the evolution of female choice. Evolution 36:1-12.

KLuge, A. G. 1981. The life history, social organization, and parental behavior of Hyla rosenbergi Boulenger, a nest-building gladiator frog. Misc. Publ. Mus. Zool. Univ. Mich. 160:1-170.

KRUSE, K. C. 1981. Mating success, fertilization potential, and male body size in the American toad (Bufo americanus). Herpetologica 37:228233.

LANDE, R. 1980. Sexual dimorphism, sexual selection, and adaptation in polygenic characters. Evolution 34:292-305.

- 1981. Models of speciation by sexual selection on polygenetic traits. Proc. Nat. Acad. Sci. USA 78:3721-3725.

LeE, J. C., AND M. L. CRumP. 1981. Morphological correlates of male mating success in Triprion petasatus and Hyla marmorata (Anura: Hylidae). Oecologica 50:153-157.

Licht, L. E. 1975. Comparative life history features of the western spotted frog, Rana pretiosa, from low- and high-elevation populations. Can. J. Zool. 53:1254-1257.

ㄴ._. 1976. Sexual selection in toads (Bufo americanus). Can. J. Zool. 54:1277-1284.

MCDiarmid, R. W. 1978. Evolution of parental care in frogs, pp. 127-147. In G. M. Burghardt and M. Bekoff (eds.), The Development of Behavior: Comparative and Evolutionary Aspects. Garland STPM Press, N.Y.

PARKer, G. A. 1983. Mate quality and mating decisions, pp. 141-166. In P. Bateson (ed.), Mate Choice. Cambridge Univ. Press, Cambridge, U.K.

Payne, R. B., And K. Payne. 1977. Social organization and mating success in local song populations of village indigobirds (Vidua chalybeata). Z. Tierpsychol. 45:113-173.

Price, T. D. 1984. Sexual selection on body size, territory and plumage variables in a population of Darwin's finches. Evolution 38:327-341. 
RYAN, M. J. 1980a. Female mate choice in a neotropical frog. Science 209:523-525.

$1980 b$. The reproductive behavior of the bullfrog (Rana catesbeiana). Copeia 1980:108114.

- 1983. Sexual selection and communication in a Neotropical frog, Physalaemus pustulosus. Evolution 37:261-272.

Savage, R. M. 1961. The Ecology and Life History of the Common Frog (Rana temporaria). Hafner, N.Y.

SeIGEL, R. A. 1983. Natural survival of eggs and tadpoles of the wood frog, Rana sylvatica. Copeia 1983:1096-1098.

SHINE, R. 1979. Sexual selection and sexual dimorphism in the Amphibia. Copeia 1979:297306.

Sullivan, B. K. $1982 a$. Sexual selection in the Great Plains toad (Bufo cognatus). Behaviour 3: 258-264.

- 1982b. Male mating behaviour in the Great Plains toad (Bufo cognatus). Anim. Behav. 30:939-940.

- 1982c. Sexual selection in Woodhouse's toad (Bufo woodhousei). I. Chorus organization. Anim. Behav. 30:680-686.

-1983. Sexual selection in Woodhouse's toad (Bufo woodhousel). II. Female choice. Anim. Behav. 31:1011-1017.

Trivers, R. L. 1972. Parental investment and sexual selection, pp. 136-179. In B.G. Campbell (ed.), Sexual Selection and the Descent of Man 1871-1971. Aldine, Chicago.

VerRell, P. A. 1983. Some problems in the study of anuran pairing patterns. Oikos 41:148-149.

WADE, M. J. 1979. Sexual selection and variance in reproductive success. Amer. Natur. 114:742747.

Wade, M. J., ANd S. J. Arnold. 1980. The intensity of sexual selection in relation to male sexual behaviour, female choice, and sperm precedence. Anim. Behav. 28:446-461.

WeLLS, K. D. 1977a. The social behaviour of anuran amphibians. Anim. Behav. 25:666-693.

- 1977b. Territoriality and male mating success in the green frog (Rana clamitans). Ecology 58:750-762.

-1978. Territoriality in the green frog (Rana clamitans): vocalizations and agonistic behaviour. Anim. Behav. 26:1051-1063.

- 1979. Reproductive behavior and male mating success in a Neotropical toad, Bufo typhonius. Biotropica 11:301-307.

Whitney, C. L., AND J. R. KReBS. 1975a. Mate selection in Pacific tree frogs. Nature 255:325326.

- 1975b. Spacing and calling in Pacific tree frogs, Hyla regilla. Can. J. Zool. 53:1519-1527.

Wilbur, H. M., D. I. RubensteIN, AND L. FairCHILD. 1978. Sexual selection in toads: The roles of female choice and male body size. Evolution 32:264-270.

Woodward, B. D. 1982. Sexual selection and non-random mating patterns in desert anurans (Bufo woodhousei, Scaphiopus couchi, S. multiplicatus and $S$. bombifrons). Copeia 1982:351355.

WoOLBright, L. L. 1983. Sexual selection and size dimorphism in anuran Amphibia. Amer. Natur. 121:110-119.

WriGHT, A. H. 1914. Life histories of the anura of Ithaca, New York. Carnegie Inst., Wash. DC.

Wright, A. H., AND A. A. WRIGHT. 1949. Handbook of Frogs and Toads of the United States and Canada. Comstock, Ithaca, NY.

Corresponding Editor: J. A. Endler

\section{APPENDIX}

The methods used to estimate annual mating and reproductive success in wood frogs are complicated because the effects of both polygyny and sex ratio bias must be considered. Our calculations are based on the 1981 breeding season. In that year, the breeding population contained 4,631 males and 1,964 females; these figures differ from those reported in Figure $1 \mathrm{~B}$ because they have been corrected for the accidental deaths of individuals that occurred during our handling procedures.

Data used in estimating mating and reproductive success in our study come from a sample of 568 pairs of wood frogs that we observed produce fertile egg masses. Females mated with one male, whereas males mated with as many as three females. As a result, our sample consisted of 568 females and 524 males. Body sizes of all parents were measured immediately after oviposition.

Mating Success. - Table 4 summarizes the mating patterns for male and female wood frogs. For both sexes, we report the number and relative fre-

TABLE 4. Number of male wood frogs in three categories of mating success and number of females that mated with males of each category.

\begin{tabular}{|c|c|c|c|c|c|}
\hline \multirow{2}{*}{$\begin{array}{l}\text { Male mating } \\
\text { success } \\
\text { category }\end{array}$} & \multicolumn{2}{|c|}{ Males } & \multicolumn{3}{|c|}{ Females } \\
\hline & $\begin{array}{l}\text { Number } \\
\text { observed }\end{array}$ & $\begin{array}{c}\text { Sample } \\
\text { frequency }\end{array}$ & $\begin{array}{l}\text { Number } \\
\text { observed }\end{array}$ & $\begin{array}{c}\text { Sample } \\
\text { frequency }\end{array}$ & $\begin{array}{l}\text { Estimated number } \\
\text { in population }\end{array}$ \\
\hline Monogamy & 482 & 0.9199 & 482 & 0.8486 & 1,667 \\
\hline Bigamy & 40 & 0.0763 & 80 & 0.1408 & 276 \\
\hline Trigamy & 2 & 0.0038 & 6 & 0.0106 & 21 \\
\hline Totals & 524 & 1.0000 & 568 & 1.0000 & 1,964 \\
\hline
\end{tabular}


TABle 5. Estimated number of matings per male wood frog in the population.

\begin{tabular}{lrrrr}
\hline \hline & \multicolumn{5}{c}{1981} \\
\cline { 2 - 5 } & 0 & 1 & 2 & 3 \\
\hline $\begin{array}{c}\text { Number of } \\
\text { males }\end{array}$ & 2,819 & 1,667 & 138 & 7 \\
$\begin{array}{c}\text { Sample } \\
\text { frequency }\end{array}$ & 0.6087 & 0.3621 & 0.0298 & 0.0015 \\
\hline
\end{tabular}

quency of individuals categorized by their own mating success (males) or that of their mates (females). For females, we extend our sample data to predict the number of each type of female in the population. Similar population estimates for males require information on the effects of polygyny and sex ratio (Table 5). First, the number of males obtaining one mating is 1,667 (the number of females that mated with monogamous males); the number of males achieving two matings is 138 (half the number of females that mated with bigamous males); and the number of males achieving three matings is 7 (onethird the number of females that mated with trigamous males). Thus, 1,812 males (39.1\%) mated at least once and 4,631 - 1,812=2,819 males went unmated (Table 5). Of the 2,819 unmated males, $4,631-1,964=2,667$ males $(57.6 \%)$ did not mate because of the shortage of females; the remaining $2,819-2,667=152$ males $(3.3 \%)$ went unmated as a result of the polygynous activity of other males. The estimated frequencies and the mating success statistics $(\bar{x}=0.425, \mathrm{SD}=0.559, \mathrm{CV}=131.53)$ were then extrapolated to the entire male population from these data.

Reproductive Success. - Estimates are expressed in number of zygotes per parent. Unlike the preceding analysis, we base all summary RS statistics on the original sample of 568 matings rather than on population projections. The number of oviducal eggs, illustrated in terms of body size, was used to estimate female RS. We employed the regression equation, $Y=51.066 X-1574.7$, extracted from the female clutch size : body size relationship, and the body sizes of the 568 known parents to determine male RS. This parameter was estimated first for males with the highest degree of polygyny. We solved for the number of zygotes in the last clutch fertilized by a trigamous male, using the regression equation and the body size of the female parent involved. Because we did not record the identity of each individual male in our sample, the numbers of zygotes in each of the remaining two matings were estimated by randomly selecting a previously mated male of the same body size as the trigamous male in question and, with the size of that male's mate, solving for number of zygotes. The same procedure was used to estimate the numbers of zygotes in the clutches sired by bigamous individuals. Monogamous males were all those males remaining in the sample, and their RS was determined using the described regression technique.

Some number of unmated males must be included in our sample if the estimate of average male RS is to reflect accurately all degrees of mating success that occur in the population. We know that a total of 524 males actually mated in our sample of 568 observed matings. To estimate the number of unmated males relevant to 568 females we solved for number of males $(X)$ by using the overall population sex ratio,

$$
\begin{aligned}
\frac{X}{568} & =\frac{4,631}{1,964}, \\
X & =1,339,
\end{aligned}
$$

and subtracting the number of males known to have mated in the observed sample $(1,339-524=815)$. Thus, 815 entries of males siring zero zygotes were used to estimate male RS statistics $(\bar{x}=244.10$, $\mathrm{SD}=334.56, \mathrm{CV}=137.06$ ). For a hypothetical population with a $1: 1$ sex ratio, we assumed our sample consisted of 568 males and 568 females. Because 524 males mated successfully, 44 entries of males siring zero zygotes were used to estimate male RS statistics $(\bar{x}=575.45, \quad \mathrm{SD}=270.41$, $\mathrm{CV}=46.99$ ). 